SPACE DYNAMICS AND CELESTIAL MECHANICS 


\title{
SPACE DYNAMICS \\ AND \\ CELESTIAL MECHANICS
}

PROCEEDINGS OF THE INTERNATIONAL WORKSHOP,

DELHI, INDIA, 14-16 NOVEMBER 1985

\section{EDITED BY}

K. B. BHATNAGAR

Zakir Husain College,

University of Delhi, India

\author{
D. REIDEL PUBLISHING COMPANY \\ A MEMBER OF THE KLUWER \\ ACADEMIC PUBLISHERS GROUP




\section{Library of Congress Cataloging in Publication Data}

Space dynamics and celestial mechanics.

(Astrophysics and space science library; v. 127)

Proceedings of the International Workshop on Space Dynamics and Celestial Mechanics organized by the University of Delhi, Delhi, Vikram Sarabhai Space Centre, Trivandrum, India, and the Space Programme of the University of Texas at Austin, Austin, U.S.A.

Includes index.

1. Mechanics, Celestial-Congresses. 2. AstrodynamicsCongresses. 3. Solar system-Congresses. 4. Satellites-Congresses. I. Bhatnagar, K. B. II. International Workshop on Space Dynamics and Celestial Mechanics (1985: Delhi, India) III. Vikram Sarabhai Space Centre. IV. University of Texas. Space Programme. V. Series.

QB349.S69 $1986 \quad 521.1 \quad 86-15527$

ISBN-13: 978-94-010-8603-5

e-ISBN-13: 978-94-009-4732-0

DOI: $10.1007 / 978-94-009-4732-0$

Published by D. Reidel Publishing Company, P.O. Box 17, 3300 AA Dordrecht, Holland.

Sold and distributed in the U.S.A. and Canada by Kluwer Academic Publishers, 101 Philip Drive, Assinippi Park, Norwell, MA 02061, U.S.A.

In all other countries, sold and distributed by Kluwer Academic Publishers Group, P.O. Box 322, 3300 AH Dordrecht, Holland.

All Rights Reserved
๑ 1986 by D. Reidel Publishing Company, Dordrecht, Holland

Softcover reprint of the hardcover 1st edition 1986

No part of the material protected by this copyright notice may be reproduced or utilized in any form or by any means, electronic or mechanical including photocopying, recording or by any information storage and retrieval system, without written permission from the copyright owner 


\section{DEDICATION}

It is with great affection and regard that we dedicate this volume to Victor Szebehely who inspires one and all in the persuit of knowledge. We have known a multitude of people but he is indeed unique in arousing in us feelings, those searing tender and deep feelings, we hardly get the experience in our life-time. His personality radiates a soothing aroma. And we are sure, this soothing radiation will survive the joys and all the woes of man. 
TABLE OF CONTENTS

Dedication

Preface

$\mathrm{xi}$

Group Photograph

xiv

List of Participants

$\mathrm{XV}$

Part I: Key Note Address

V.SZEBEHELY/New Nondeterministic Celestial Mechanics.

Part II: General Celestial Mechanics

A.AHMAD and M.N. HUDA/Periodic Solution of the Three-Dimensional Restricted Three Body Problem Representing Analytic Continuation of Keplerian Rectilinear Periodic Motion.

MANJU KUMARI and R.K. CHOUDHARY/Stability of Lagrange's Particular Solution in the Plane Photogravitational Unrestricted Problem of Three Bodies.

SHANON L. COFFEY, A. DEPRIT and BRUCE R. MILLER/The Nature of the Critical Inclinations in Artificial Satellite Theory.

A. ELIPE and MERCEDES ARRIBAS/An Extension of Jacobian Constant.

B. GARFINKEL/On the Last BROWN Conjecture.

QUI-DONG WANG, ZHAO-HUA YI and JING YONG CHENG/Qualitative Study of N-Body Problem: Unitized Momentum Transformation and its Application.

R.K. SHARMA and P.V. SUBBA RAO/On Finite Periodic Orbits Around the Equilateral Solutions of the Planar Restricted Three-Body Problem.

S.K. SHRIVASTAVA and S. PRADEEP/Stability of Time Varying Linear Systems .

JOSE M. FERRÁNDIZ and ANA FERNANDEZ-FERREIRÓS/A New Transformation of the Two-Body Problem to Oscillator Form.

Part III: Solar System and Natural Satellites

Y. KOZAI/Stability of Motions of Asteroids.

T. PAUWELS/On the Possibility of a "CUCKOO-EFFECT" in the Earth-Moon System. 
S.D. VERMA/Influence of Planetary Motion and Radial Alignment of Planets on Sun.

R.0. VICENTE/Stability and Evolution of the Minor Bodies of the Solar System.

Part JV: Stellar Systems and Galaxies

G. ALAGAR RAMANUJAM and P. ACHUTHAN/Trajectory of Space - Like Particles in a Schwarzchild Field.

S.M. ALLADIN/The Dynamics of Satellite Stellar Systems.

V.A. BRUMBERG, T.V. IVANOVA and S.V. TARASEVICH/Orbital Evolution of Massive Close Binary Under the Influence of Small Bodies.

N. CARANICOLAS and TH. DIPLAS/Dynamical Systems with Simple Periodic Solutions.

D. GALLETTO and B. BARBERIS/Extragalactic Celestia1 Mechanics: The Equation of Evolution.

S.D. MATHUR/Sma1I Oscillations of Collisionless Gravitating Systems .

P.M.S. NAMBOODIRI and R.K. KOCHHAR/Numerical Experiments on the Formation of Tails and Bridges in Galaxies.

Part V: Orbit Determination and Satellite Theory

V. ADIMURTHY, P.V. SUBBA RAJU, D.R. MANOHAR, P.VILASINI and RADHIKA B. RAMNATH/Injection State Vector Estimation from Flight Data Analysis of a Spinning Apogee Stage.

J.A. CABALLERO, S.FERRER and M.L. SEIN-ECHALUCE/Second Order Solution of a Radial Intermediary in Satellite Theory.

N. GEORGIEV/Utilization of Analytical Methods for Orbit Determination in High Accuracy Geodetic Positioning.

J. HENRARD/Analytical Drag Theory of an Artificial Satellite with Small Eccentricity.

HUANG CHENG and HE MIAO-FU/A Refined Analysis of the Perturbations on Lageos.

LEELAMMA MANI and V. SWAMINATHAN/A Computer Program for Orbit Determination Using the KALMAN FILTER Approach.

R.B. SINGH/Non-1inear Planar Oscillation of a Satellite in E11iptical orbit under the Influence of External Forces of General Nature. 
D. SITA RAMA RAJU, CH. SREEHARI RAO and S.K. SHRIVASTAVA/Early Orbit Determination Using U-D Covariance Propagation Filter. 309

Part VI: Attitude Motion

P.S. GOEL, P.NATARAJAN and P. KUDVA/Sate11ite Attitude Acquisition by a Momentum Bias System.

P.S. GOEL, K.S. CHANDRA and P. KUDVA/Observer Based Design of Normal Mode Attitude Control for IRS Satellite.

P.S. GOEL, R.S. RAWAT and S. BALAJI/Magnetic Yaw-Ro11 Contro1 and Momentum Dumping for SROSS.

J.KOVALEVSKY and E.BOIS/Attitude Determination of the HIPPARCOS Satellite.

K. HARENDRA NATH, A.S. GANESHAN, K.K. ACHARY and S.C.RATHANAKARA/ Attitude Determination of a Powered Launch Vehicle Stage With Conventional Satellite Sensors.

Part VII: Mission Planning and Control

K.K. BISWAS/Some Aspects of Jettisoning Dynamics Related to Launch Vehicle.

J.P. CARROU/Zoom Software: Error Analysis and Accurate Orbit Restitution at CNES.

R.L. DUNCOMBE, A.L. WHIPPLE and P.D. HEMENWAY/Orbit Correction Using Jefferys' Method of Least Squares.

M.C. ECKSTEIN/Station Keeping Strategy Test, Design and Optimization by Computer Simulation.

A.F. LEIBOLD and C.K. RAJASINGH/Optimal Injection into Near Synchronous Orbit by Three Apogee Motor Burns Accounting for Operational Constraints and Execution Errors.

P.R. MAHAPATRA/New Results on Proportional Navigation Trajectories.

Resolution

Author Index

Subject Index 


\section{PREFACE}

This volume contains the detailed text of the lectures delivered at the International Workshop on Space Dynamics and Celestial Mechanics held in Delhi, India during November 14-16,1985. This workshop was organised under the joint sponsorship of University of Delhi, Delhi, Vikram Sarabhai Space Centre, Trivandrum (India) and the Space Programme of the University of Texas at Austin, Austin, USA.

The main objective of the workshop was to review the current state of the art in the area of Space Dynamics and Celestial Mechanics through paper presentations, key note addresses, lectures and discussions, to expose the participants to more recent developments in various techniques, analytical as well as numerical, as applicable to Space Mechanics, to identify and assess the degree of augmentations desirable in respect of software packages available for this purpose with different centres and to establish contacts with experts in the vital field with a view to facilitate the in flow of technical information.

The whole material of this volume has been organized into seven basic areas:

(i) The key note address by Professor V. Szebehely, (ii) General Celestial Mechanics, (iii) Solar System and Natural Satellites, (iv) Stellar Systems and Galaxies, (v) Orbit Determination and Satellite Theory, (vi) Attitude Motion and (vii) Mission Planning and Control.

(i) Prof. Szebehely in his key note address discusses the non-deterministic nature of celestial mechanics and its relation to stability investigations. His paper first defines the concepts to be used, lists reasons for indeterminism and offers several examples. This is followed by a discussion of stability as related to determinism. The role of uncertainties and important time scales are treated next. The existence of integrals and transformations of dynamical systems are shown to be beneficial to determinism but in fact they only delay the built in catastrophic trends.

(ii) The most well known unsolved problem of celestial mechanics is the N-Body Problem. In this part the various aspects of the two-body problem and the three-body and many body problems have been presented. We know that the so-called triangular libration points of the restricted problem of three bodies show stability provided the mass parameter of the problem is below a certain critical value. When the centrifugal, gravitational and coriolis forces are modified with proper parameters, this well known stability can undergo significant changes. Furthermore the participating primary masses in the restricted problem of three bodies are usually considered point masses. If this assumption is substituted by more realistic models where the primaries are bodies of finite dimensions with various gravitational properties, the stability is effected. One or the other problems mentioned above have been presented by Drs. Ahmed, Chaudhry, Elipe, Quidong, Sharma and Ferrindiz.

In this part the paper presented by $\mathrm{Dr}$. Deprit is also included. He has studied the nature of the Critical Inclination in the Artificial Satellite Theory. He has shown that manifolds of orbits with stationary perigees are intrinsic features of the averaged main problem in this 
theory; they bifurcate off the manifold of circular orbits at the points where stability flips to instability and vice-versa.

(iii) The third part of this volume is dedicated to the study of the Solar System and Natural Satellites. Drs. Kozai, Pauwe1s, Verma and Vicente presented papers on these subjects.

(iv) In the fourth part papers relating to problems on Stellar systems and galaxies are included. Dr. Brumberg studies the orbital evolution of massive close binary under the influence of small bodies. Dr. Galletto presents a paper on Extra Galactic Celestial Mechanics. The equation of evolution of the universe is deduced with reference to both the isotropic and the anisotropic cases without resorting to the Newtonian Theory of Gravitation.

The motion of a star in a satellite stellar system is governed by the force due to the over-all distribution of matter in the system, the force due to stellar encounters within the system and the tidal force due to the primary stellar system. Drs. Alladin and Namboodri have studied the effects of the tidal force and have shown that interacting galaxies have peculiar features like tails and bridges and counterarms of various sizes and shapes.

Dr. Alagar has presented the problem of determining the trajectories of a tachyonic celestial object in a Schwarzchild field.

(v) In part $V$ papers relating to orbit determination and satellite theory are included. A large number of artificial earth satellites are put in orbit at low altitudes. The dominant perturbation on their orbit is due to atmospheric drag. Dr. Henrard has presented an analytical drag theory of an artificial satellite with small eccentricity. A11 the formulas are presented in explicit form from osculating elements at epoch to osculating elements at date. Dr. Ferrer and his coauthors have revised the zonal earth satellite theory.

Dr. R.B. Singh has presented the analysis of nonlinear planar oscillation of a satellite launched in an elliptical orbit under the influence of external forces of general nature such as accretion and tidal effects etc.

(vi) This part is devoted to the study of the Attitude Determination of Satellites. Dr. Kovalevsky's paper deals with the attitude determination of the Hipparcos satellite. Dr. Goel and his co-authors have presented a study on the magnetic yaw-roll control and momentum dumping for the SROSS spacecraft and in another paper they have presented a study on the attitude and orbital control system for the Indian Remote Sensing (IRS) satellite to be put into sun-synchronous $100^{\prime}$ Clock polar orbit during 1986. Dr. Nath and his colleague's paper is dedicated to the attitude determination of a powered launch vehicle.

(vii) The Indian Space Research Organisation (ISRO) sent a very strong delegation of about 50 scientists to participate in the Workshop. A large number of scientific papers of very high standard were presented. Some of the papers could not be included in this volume due to various reasons beyond the control of the editor. This part of the volume is dedicated to the mission planning and control and some of the papers in this category were presented by scientists of ISRO. Papers on Jettisoning Dynamics, Zoom Software, Optimal Injection with near synchronous orbit and proportional navigation trajectories, orbit 
correction etc. have been presented by Drs. Biswas, Carrou, Eckstein, Leibold, Raja Singh and Mahapatra.

Several papers were dicated to the fundamentals such as Hamiltonian Mechanics, BMK theory, Lunar theory, Resonance theory and Stability. Lectures on bifurcation, on integrability, on regularization, on manifolds, on deterministic and non-deterministic systems etc. are included.

The most of the lectures delivered were lucid and understandable to the participants who had solid background in Dynamics and Celestial Mechanics. Each lecture was followed by free and frank discussions. We do thank all the participants who took keen interest in the deliberations of the Workshop.

As the readers will agree, the Workshop gave an opportunity to the participants to know the most recent developments in the area of space Dynamics and Celestial Mechanics and to make contacts with scientists coming from every corner of the world.

At the end of the Workshop the Indian Scientists passed a resolution which was also approved by the non-Indian Scientists. The resoluis given at the end of the book.

We are most grateful to the authorities of the University of Delhi, Delhi; Vikram Sarabhai Space Centre, Trivandrum and the Space Programme of the University of Texas at Austin, Austin for sponsoring this

Workshop. We do express our thanks to the Department of Science and Technology, Delhi; the University Grants Commission, Delhi; the Council of Scientific and Industrial Research, Delhi; the Department of Training and Sponsored Research Delhi; the Tata Institute of Fundamental Research, Bombay; the Indian Space Research Organisation and the Sahitya Kala Parishad,Delhi which supported our Workshop. Finally, we do thank all the organisations which supported many participants to attend this Workshop.

At the end, I would like to thank Dr. (Mrs.) Usha Gupta who devotedly and tirelessly assisted me in the preparation of this volume. She is my student, my colleague and my friend. My thanks are also due to Drs. S.A. Ali, B.S. Yadav, G.C. Ahuja, A.Iqba1, M.L. Agarwa1, P.P. Hallan, S.C. Jethi, D.S. Jaggi, V. Sharda and Mr. H.R. Mehra for assisting me in organising the Workshop. I would also like to thank all the members of the International Organising Committee, Advisory Commitee and the Local Organising Committee for their valuable advise in planning and successful completion of the Workshop.

K.B. Bhatnagar

Chairman,

International Workshop and

Editor of the Proceedings 


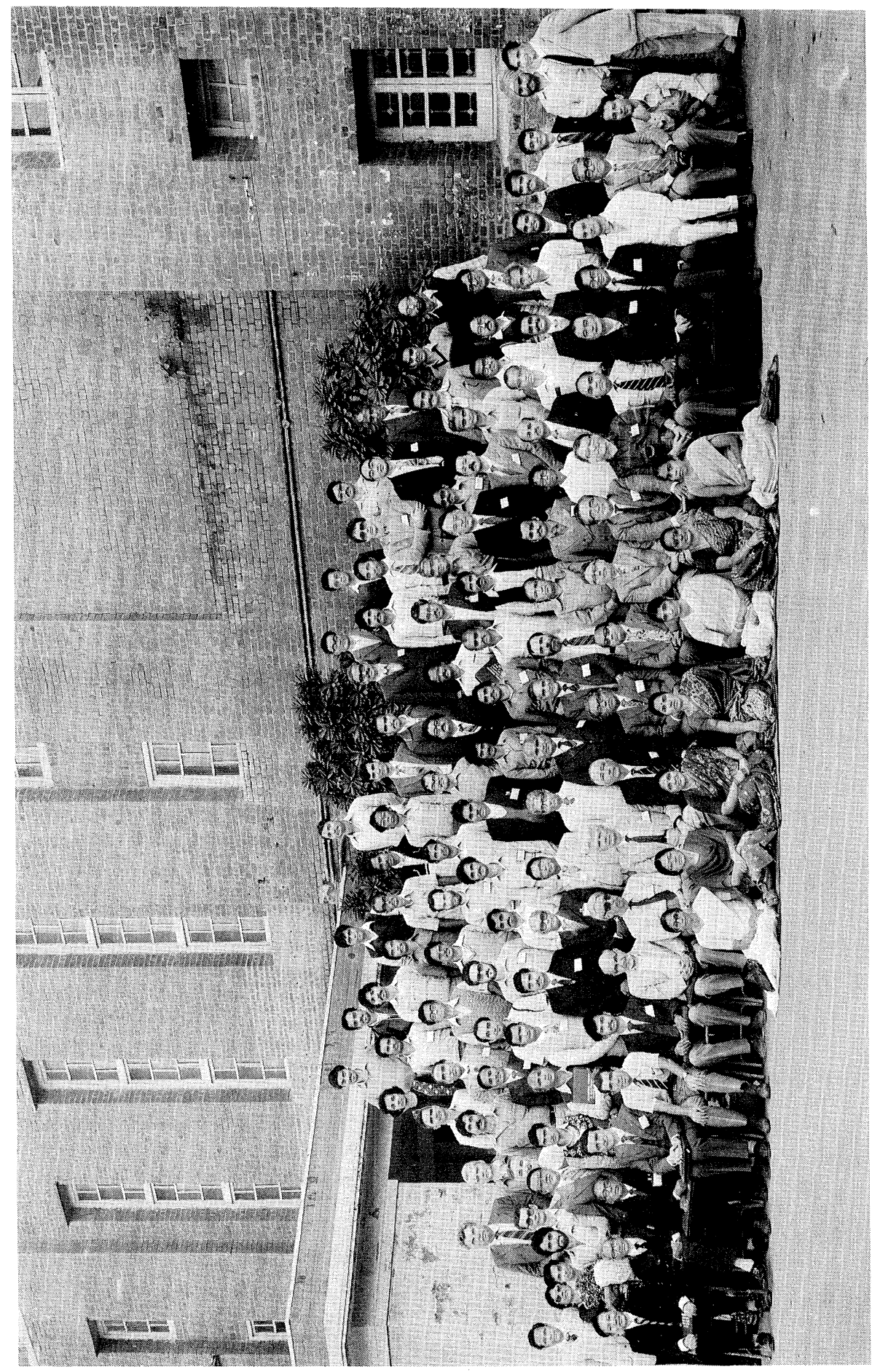




\section{LIST OF PARTICIPANTS}

1. Adimurthy, V.

2. Aggarwal, M.K.

3. Aggarwal, M.L.

4. Aggarwal, P.D.

5. Aggarwal, S.P.

6. Ahmad, A.

7. Ahuja, G.C.

8. Alladin, S.M.

9. Anjaneyulu, M.

10. Antuvan, D.S.

11. Bagga, P.C.

12. Balasubramaniam, S

13. Ballabh, G.M.

14. Baveja, S.D.

15. Bhatnagar, K.B.
(India) Head, A.R.D., V.S.S.C., Trivandrum.

(India) Survey of India, Raipur.

(India) Statistics Department, University of Delhi,Delhi-110007.

(India) I.S.I. Division, V.S.S.C., Trivandrum.

(India) Defence Science, Metcalf House, Civil Lines, Delhi.

(India) Department of Mathematics, Sahibganj College, Sahibganj (Bihar).

(India) Department of Mathematics, University of Delhi, Delhi.

(India) Department of Astronomy, Osmania University, Hyderabad-500007.

(India) V.S.S.C., PSLV Project, Trivandrum.

(India) V.S.S.C., ASLV Project, Trivandrum.

(India) Motilal Nehru College, Evening Classes, Motibagh, New Delhi.

(India) Sci/Engineer Sc. ISTRAC, Shar Centre, Sriharikota, Nellore Distt., A.P.

(India) Associate Astronomer, Department of Astronomy, Osmania University, Hyderabad.

(India) D.D. R\&D, Survey of India, E.C. Road, Dehradun-248001.

(India) Department of Mathematics, Zakir Husain College, Ajmeri Gate, Delhi-6. 
16. Bhattacharya, K.C.

17. Biswas, K.K.

18. Brumberg, V.A.

19. Caranicolas, N.

20. Carrou, J.P.

21. Chandra, K.S.

22. Chatterji, S.K.

23. Chatterji, T.K.

24. Chopra, S.D.

25. Choudhry, R.K.

26. Cui Dou-Xing

27. Davis, M.S.

28. Deprit, A.

29. Doggett, L.E.
(India) ISI Division, VSSC, Trivandrum-695022.

(India) Manager, Software System, ARD, VSSC, Trivandrum-695022.

(USSR) Institute of Theoretical Astronomy, 191187, Leningrad.

(Greece) Astronomy Department, University of Thessaloniki, Thessaloniki.

(France) Centre National, D'etudes Spatiales, 18, Avenue Edouard Belin, 31055, Toulouse Cedex.

(India) ISAC, Airport Road, Bangalore-17.

(India) A-9/1, Vasant Vihar, New Delhi.

(India) Department of Astronomy, Osmania University, Hyderabad.

(India) Department of Mathematics, Kurukshetra University, Kurukshetra.

(India) Department of Mathematics, Bhagalpur University, Bhagalpur.

(China) Changhun Artificial Satellite Observatory, P.0. Box 1067, Changhun, Kirin.

(U.S.A.) University of North Carolina, Chapel Hil1, North Carolina-27514.

(U.S.A.) United States Department of Commerce, National Bureau of Standard, Gaitherburg, Maryland-20899.

(U.S.A.) U.S. Naval Observatory, Washington, D.C. 20390. 
30. Duncombe, R.L.

31. Dybczynski, P.A.

32. Eckstein, M.C.

33. Elipe, A.

34. Ferrandiz, J.M.

35. Ferrer, S.

36. Fiala, A.D.

37. Galletto, D.

38. Ganguli, A.K.

39. Carfinkel, B.

40. Georgiev, N.I.

41. Goel, S.

42. Goyal, V.K.
(U.S.A.)

Department of Aerospace Engineering and Engg. Mechanics, University of Texas at Austin, Austin, Texas-78712.

(Poland) Astronomical Observatory of the A.M. University, Slonegna, 36-60-286, Poznan.

(Germany) DFVLR-GSOC-OBERPFAFFENHOFEN 8031, Wessling, Federal Republic of Germany.

(Spain) Departmento De Astronomia, Universidad De Zaragoza, Zaragoza-50009.

(Spain) Departmento De Matematica Aplicada, E.T.S. Ingenieros Industriales, 47010, Valladolid.

(Spain) Departmento De Astronomia, Universidad De Zaragoza, Zaragoza-50009.

(U.S.A)

U.S. Naval Observatory, Washington, D.C. 20390.

(Italy) Instituto Di Firco Mathematica, J-Lovis Lagrange University of Torino Via Carlo, Alberts 10-10123, Torino.

(Assam) Department of Mathematics, Konoi College, Dibrugarh.

(U.S.A) Department of Astronomy, Yale University, New Haven, CT-6511.

(Bulgaria) Central Laboratory for Geodesy, Bulgarian Academy of Science, "7 November" -Street No.1, 1000 Sofia.

(India) Department of Mathematics, Zakir Husain College, Delhi.

(India) ARD/VSSC, Trivandrum-695022. 
43. Gupta, B.

44. Gupta, S.D.

45. Gupta, U.

46. Hallan, P.P.

47. Handoo, K.L.

48. He Miafu.

49. Henrard, J.

50. Huda, M.N.

51. Iqbal, A.

52. Ishwar, B.

53. Iyer, R.P.

54. Jagdish Singh

55. Jaggi, D.S.

56. Jethi, S.C.

57. Joshi, C.S.
(India)

(India)

(India)

(India)

(India)

(China)

(Belgium)

(India)

(India)

(India)

(India)

(India)

(India)

(India)

(India)
Department of Mathematics, Lakshmibai College, Ashok Vihar-III, Delhi-52.

Engineer S.F. Central and Guidance Division, V.S.S.C., Trivandrum.

Department of Mathematics, Dayal Singh College, Delhi.

Department of Mathematics, Zakir Husain College, Delhi

ASTR, V.S.S.C., Trivandrum-695022.

Shanghai Observatory, Academia Sinica Shanghai, People's Republic of China.

Facultes Universitoores, De Namur, 8 Rehpart De La Vierge 5000 Namur.

C/o Dr. A.Ahmed, Department of Mathematics, Sahibganj College, Sahibganj (Bihar).

Department of Mathematics, University of Delhi, Delhi.

Department of Mathematics, Bihar University, Muzaffarpur.

Supt. Surveyor, Survey of India, Hyderabad.

Hind Pharmacy, Main Road, Begusarai, 854101-Bihar.

Department of Mathematics, Zakir Husain College, Delhi.

Department of Mathematics, Dayal Singh College, Delhi.

Deputy Director, Geodetic and Research Branch, 17-EC Road, Dehradun. 
58. Jothivelu, $\mathrm{K}$.

59. Kalra, G.L.

60. Kapur, R.K.

61. Kararha, K.L.

(India)

62. Khairozzaman,A.E.M. (India)

63. Khan, A.

64. Kishori Lal

65. Koul, J.

66. Kovalevsky, J .

67. Kozai, Y.

68. Krishnamurthy, K. (India)

69. Krishnamurthy, M. (India)

70. Krishnan, V.

71. Lal, P.K.

72. Leibold, A.F.

73. Lochan, R.

74. Madan Lal
(India)

(India)

(India)

(India)

(India)

(France)

(Japan)

(India)

(Germany)

(India)
Engineer, SE, ARD, V.S.S.C., Trivandrum.

Department of Physics, University of Delhi, Delhi.

Supt. Survey, Satellite Geodesy Party, S OI, 111/3, Rajpur Road, Dehradun.

O.C. No. 72, Party (G\&R.V.), Survey of India, Dehradun.

Department of Physics, B.N. College, Dhubri.

Department of Mathematics, Zakir Husain College, Delhi.

ARD, VSSC-Trivandrum-695022.

Department of Astronomy, Osmania University, Hyderabad.

Cerga, Avenue Copernic, F-06130, Grasse.

Tokyo Astronomical Observatory, Mitaka, Tokyo 181.

Engineer, ARD, VSSC Trivandrum.

Deptt. of Aeronautical Engineering, I.I.T., Kanpur.

Engg. SF, I.S.I., V.S.S.C., Trivandrum.

C/o Dr. R.N. Lal, At \& P.O. Nathnagar, Distt. Bhagalpur-812006.

DFVLR-GSOC-OBERPFAFFENHOFEN, 8031 Wessling-Federal Republic of Germany.

ARD/VSSC., Trivandrum, 695022.

ARD/VSSC., Trivandrum, 695022. 
75. Mahapatra, P.R.

76. Mahesh Kumar

77. Manak Singh

78. Mathiazhagan, S.K. (India)

79. Mary, L.

80. Mathur, J.

81. Mathur, M.C.

82. Mathur, S.D.

83. Mehra, H.R.

84. Mehra, M.

85. Mehra, V.

86. Mohan, C.

87. Muraly, L.G.M.

88. Murti, C.V.R.

89. Nagar, V.K.

90. Nagrajan, N.
(India) Department of Aerospace Engg., Indian Institute of Science, Bangalore-560012.

(India) Department of Mathematics, Prof. Colony, Station Road, Shekh Pura, Distt. Munger (Bihar).

(India) Defence Science, Metcalf House, Civil Lines, Delhi.

Programme Management Section IREX, Shar Centre, Sriharikota-524124, A.P.

(India) Stella Maris College, Madras -600086 .

(India) Department of Mathematics, Modern School, New Delhi.

(India) Director RSRPG, V.S.S.C., Trivandrum.

(India) Department of Theoretical Astrophysics, TIFR, Homi Bhabha Road, Bombay.

(India) Department of Mathematics, Zakir Husain College, Delhi.

(India) Department of Mathematics, ARSD College, Delhi.

(India) Department of Mathematics, K.M. College, Delhi.

(India) Department of Mathematics, Roorkee University, Roorkee-247672.

(India) I.S.I. Division, V.S.S.C., Trivandrum.

(India) Deptt. of Aero. Engg., I.I.T., Kanpur.

(India) Deputy Director, Survey of India, Dehradun.

(India) FDD-ISRO Sat. Centre, Bangalore-560017. 


\begin{tabular}{|c|c|c|c|}
\hline 91. & Namboodri, M.S. & (India) & $\begin{array}{l}\text { Indian Institute of Astro } \\
\text { Karamangala, Bangalore-56 }\end{array}$ \\
\hline 92. & Natarajan, P. & (India) & $\begin{array}{l}\text { ISAC, Airport Road, } \\
\text { Bangalore-17. }\end{array}$ \\
\hline 93. & Nath, K.H. & (India) & $\begin{array}{l}\text { FDD/MPDG, ISRO, } \\
\text { Satellite Centre, } \\
\text { Airport Road, } \\
\text { Bangalore-560017. }\end{array}$ \\
\hline 94. & Nautiyrl, A. & (India) & $\begin{array}{l}\text { Systems Group, D.R.D.L., } \\
\text { Hyderabad. }\end{array}$ \\
\hline 95. & Ojha, C.L. & (India) & $\begin{array}{l}\text { Deptt. of AE. IISc., } \\
\text { V.S.S.C., ARD, } \\
\text { Bangalore }-560012 \text {. }\end{array}$ \\
\hline 96. & Oli, P.V.S. & (India) & $\begin{array}{l}\text { FDD/MPDG, } \\
\text { ISRO Satellite Centre, } \\
\text { Bangalore }-560012 \text {. }\end{array}$ \\
\hline 97. & Padmanabhan, P. & (India) & $\begin{array}{l}\text { Flight Dynamics Division, } \\
\text { ISRO Satellite Centre, } \\
\text { Airport Road, } \\
\text { Bangalore. }\end{array}$ \\
\hline
\end{tabular}

98. Pande, T.C.

(India) Department of Mathematics, Berhampur University, Berhampur-760007, Orissa.

99. Pauwels, T.

(Belgium) Koninklijke Sterrenwacht Van België, Ringlaan 3, B-1180 Brussel.

100. Prabha, S.

(India) Space Application Centre, Organisational Development Training Cell, Jodhpur Tekra, Ahmedabad.

101. Prabhakaran, K.

(India) Flight Dynamics Division, Structural Engineering Division, V.S.S.C., Trivandrum.

102. Prahlad, T.S.

(India) Head, Aerospace Dynamics and Design Group, V.S.S.C., Trivandrum.

103. Prakash, A.

(India) ME/AE-Indian Institute of Science, Bangalore-560012. 
104. Prasad, K.L.

105. Prasad, P.R.

106. Raju, D.S.

107. Ramakrishna, S.

108. Ramani, S.

109. Ramanujam, G.A.

110. Rameshwar Singh

111. Ramnath, R.B.

112. Rana, N.C.

113. Rao, K.S.

114. Rauthan, D.B.

115. Sah, G.P.

116. Saseendran, B.

117. Sastry, K.S.
(India)

(India)

(India)

(India)

(India)

(India)

(India)

(India)

(India)

(India)

(India)

(India)

(India)

(India)
Appl. Math. Division, V.S.S.C. Trivandrum.

Flight Dyn. Division, ISRO Satellite Centre, Vimahpura, Mall Road, Bangalore.

Engineer-SD, ISTRAC, Shar Centre, ISRO, Sriharikota (A.P.).

Engineer Control of Guidance Division, VSSC, Trivandrum.

ISRO Computer Office, ISRO HQ, Cauvery Bhavan, Kempegowda Road, Bangalore -9 .

Department of Physics, Nallamuthu Gounder Mahalingum College, Pollachi-642001.

Department of Mathematics, Cooperative College, Begusarai (Bihar).

Aerodynamics Division, V.S.S.C., Trivandrum.

TIFR, Homi Bhabha Road, Bombay.

Deputy PD/PSLV, V.S.S.C., Trivandrum.

Insat-1, SSPO, Deptt. of Space, 10-A, Kasturba Road, Bangalore -560001 .

Department of Mathematics, H.S. College, Haveli Kharagpur Munger, Bihar.

Control and Guidance Division, V.S.S.C., Trivandrum.

Deptt. of Astronomy, Osmania University, Hyderabad. 
118. Sastry, S.S.

(India)

119. Seidelmann, P.K.

(U.S.A.)

120. Shakoor, A.A.

(India)

121. Sharma, R.K.

(India)

122. Sharma, V.N.

(India)

123. Shrivastava, S.K. (India)

124. Singh, H.S.P.

(India)

125. Singh, R.B.

(India)

126. Singh, U.N.

127. Singh, V.P.

128. Sinha, S.K.

129. Soma, P.

(India)

130. Srinivasan, B.

(India)

131. Subba Raju, P.V. (India)
Applied Maths. Division, V.S.S.C., Trivandrum.

U.S. Naval Observatory, Washington, D.C. 20390.

ISI Division, VSSC, Trivandrum-695022.

APMD, Vikram Sarabhai Space Centre, Trivandrum-695022.

Department of Mathematics, PG D.A.V. College (Evening), New Delhi.

Department of Aerospace Engg., Indian Institute of Science, Bangal ore-560009.

Department of Mathematics, M.J.K. College, University of Bihar, Bettiah-845438.

Department of Mathematics, Bihar University, Muzaffarpur.

(India) Chairman, UPSC State

Madhya Pradesh, Bhopal.

(India) Institute of Paper Technology, Saharanpur.

ISRO Head Quarters, Cauvery Bhavan, K.G. Road, Bangalore -560009 .

Manager, Space Craft Operations and Control, ISTRAC,

Shar Centre, ISRO, Sriharikota (A.P.).

Insat, MCF, Department of Space, Hassan 573201, Karnataka.

Aerodynamics Division, V.S.S.C, Trivandrum 
132. Subba Rao,P.

(India)

133. Subrahmanyam,P.V. (India)

134. Sunder, G.S.

(India)

135. Suresh, B.N.

136. Swaminathan, V.

(India)

137. Szebehely, V.

(U.S.A.)

138. Taqvi, Z.A.

139. Twakley, V.B.

140. Vedachelam, N.

141. Venkataraman, R. (India)

142. Verma, S.D.

143. Vicente, R.O.

144. Vighnesam, N.V. (India)

145. Vilasini, P.

146. Xavier, J.R.
(India)

(India)

(India)

(India)

(India)

(Portugal)

(India)
Applied Mathematics Division, V.S.S.C. Trivandrum.

Department of Astronomy, Osmania University, Hyderabad.

Indian Institute of Astrophysics, Koramangala, Bangalore -560034 .

Head, Control and Guidance Division, VSSC, Trivandrum.

Head, Applied Maths. Division, V.S.S.C., Trivandrum.

Deptt. of Aerospace Engg. and Engg. Mechanics, University of Texas at Austin, Austin, Texas-78712.

Department of Mathematics, Jamia Millia Is lamia, New Delhi.

Defence Science, Metcalf House, Civil Lines, Delhi.

Proj. Division, IGS and Head ISI, V.S.S.C., Trivandrum.

Applied Maths. Division, V.S.S.C., Trivandrum.

Department of Physics, Gujarat University, Ahmedabad-380009.

R.Mestre Aviz 30 R.C., 1495 Lisboa.

FDD/MPDG, ISRO Satellite Centre, Bangalore.

ARD/VSSC, Trivandrum-695022.

Applied Mathematics Division, V.S.S.C., Trivandrum-695022. 
147. Yadav, B.S.

(India)

Department of Mathematics, University of Delhi, Delhi.

148. Yi-Zhao-Hua

(China)

Department of Astronomy, Nanjing University, Nanjing.

149. Zhang Cheng Zhi (China)

Department of Astronomy, Nanjing University, Nanjing. 